\title{
The Child Care Worker as a Role Model
}

\author{
Harvey J. Bertcher* \\ University of Michigan School of Social Work
}

Several years ago, while working in an institution for emotionally disturbed children, I heard a housefather "raising Cain" with a 10-year old boy who had just broken a chair in a fit of temper. The housefather was angrily shouting, "By God Freddy, you better learn to control your temper, or I'll know the reason why!" With that blast, he spun around, stormed into his apartment, and slammed the door behind him.

This housefather was a perfect example of the old saying, "Do as I say, not as I do." Freddy needed to learn to control his temper but unfortunately the man who was supposed to teach him how was a very poor model of self-control.

"Role modeling" is a technical term for learning by imitation. Children learn to speak by imitating their parents; a medical student learns to play his role in an operation by watching a skilled surgeon, and so forth. Obviously, the medical student also learns about surgery by reading books, attending lectures, and dissecting a frog, but the opportunity for him to observe a skilled practitioner in action is one of the best ways for him to learn his craft.

The purpose of this paper is to set forth some of the major ideas about role modeling that have been studied, and to suggest ways in

*This paper was presented at the Michigan Association of Children's Agencies Child Care Institute, February 19, 1969. The audience consisted largely of houseparents; in addition, some supervisors, recreation workers, social workers, teachers, psychologists, and administrators were present. Requests for reprints should be sent to Harvey Bertcher, The University of Michigan School of Social Work, 1065 Frieze Building, Ann Arbor, Michigan 48104. 
which child care staff can use these ideas in their work. It is my belief that child care staff members have an excellent opportunity to serve as models of effective and appropriate behavior for the youngsters in their charge. What I should like to present are ways in which they can increase the probability that their children will use them as models; in addition, I hope to stimulate workers to think about the kind of model they now are and might like to be. After all, Freddy's housefather modeled something, even though it was not the most appropriate behavior.

I particularly want to highlight this latter point. Adults who work with children are continually modeling particular attitudes and behaviors, whether they intend to or not. Children are continually watching us, trying to discover some of the ways that we have developed to get along in the day-to-day world. If they imitate us at all, they imitate what they see and hear, not our intentions or thoughts. It therefore becomes our responsibility to continually examine the kind of model we present, and work to improve it, so that we consistently provide a good model.

\section{The Importance of Role Modeling}

Children who are placed in an institution have all been exposed to a variety of models before coming to the institution-models they could imitate in some way such as fathers, mothers, uncles, aunts, grandparents, brothers, sisters, teachers, ministers, other kids, TV heroes. Frequently these models have not demonstrated effective ways of dealing with the everyday problems of life. This might have included a father who deserted his family, a mother who drank heavily to drown her sorrows, a brother who had learned how to "hot-wire" a car for joy riding, a TV hero who solved all of his problems by beating people up, a teacher who used cruel punishments in order to control her class, and so forth; all of these and others provide negative role models - that is, models who demonstrate self-defeating or unacceptable ways of behaving.

In light of this exposure to a range of negative models, it is a wonder that children in institutions are able to produce any of the traits of behavior we usually want to encourage, such as friendliness, reliability, honesty, and fair play. That they do is evidence of two things: first, that people learn to behave the way they do from several sources, of which role modeling is only one, and second, that they may have had contact along the line with some role models who 
evidenced kindly, trustworthy, nonviolent behaviors in their presence.

The placement of a child in institutional care can be seen as an attempt to control more carefully the models with whom he comes into contact by exposing him to a number of positive models. Accordingly it is important to know as much about the process of modeling as possible in order to use it consciously and effectively.

In recent years there have been many studies related to the general topic of role modeling (Flanders, 1968; Bertcher, Gordon, Hayes, \& Mials, 1969). In looking these over there are at least three major areas that pertain to the ways in which a child care worker can increase the likelihood that he or she can use modeling effectively: one has to do with the clarity of the behavior that the model wants the observer to imitate; a second area pertains to the rewards the model receives and dispenses; the third area deals with factors of similarity between the model and the observer. Let us take these one at a time: first, clarity of behaviors.

\section{Clarity of Behaviors to Be Modeled}

Child care workers should ask themselves the following question: "What are the behaviors I perform that I would like my youngsters to imitate?" Perhaps the best way for a worker to answer this is to be able to say in precise terms just what it is that he would like the children to do more or less of, and under what kinds of conditions, for example, control their anger when a project fails so that they express themselves in words rather than in destructive acts; give expression to feelings of affection for other human beings; carry out cottage jobs responsibly when given an assignment; eat with acceptable table manners at dinner time; take good care of cottage equipment when child care staff members are not present; participate in competitive sports according to the rules of fair play; and so forth.

Let us say that the worker has decided that he wants some children to model "affectionate" behaviors. This can create problems. For example, child care staff often try not to "play favorites," and as a result may hold back in expressing affection for particular children. Although it is wise to avoid getting a "pet," children may need to see a model demonstrating the normal and acceptable ways of expressing affection. A worker might be able to model this toward other youngsters, fellow staff, or, if he happens to be one half of a houseparent couple, toward his spouse. Suppressing affectional gestures deprives children of this kind of modeling. 
A worker may want a child to do more of something (as in the example above) and therefore he would model affectionate behaviors for the child. But what if he wants him to do less of something-how does he model that? For example, perhaps the worker wants a child to cut down on shouting when communicating with others. How does the worker model "less shouting?" It is important to remember that he is not simply asking the child to shout less, he is also hoping that the child will learn to speak in a moderate tone of voice. In other words, for every behavior to be diminished, some other behavior is to be increased.

There is a difference between sheer imitation and modeling. It is not necessary for a child to end up as a carbon copy of a worker; for example, practicing being affectionate to the worker's spouse in the same way that the worker is. Nevertheless it is true that people sometimes learn how to perform a role by first imitating a model, word for word, gesture for gesture. Hopefully this changes in time, and the individual develops the role in his own style, borrowing some major themes from the model but varying the tune to keep it in harmony with his own personality.

For example, given a housefather who mastered his anger by slowly counting to 10 , Freddy might also use a " 10 count" to gain control of himself; in time he may discover that one or two well-chosen words do just as well; eventually he may learn that it works even better when he says these words to himself, rather than out loud. The important point is that he has learned to control his temper by imitating a technique that works well for his housefather.

Once the worker is clear in his own mind about the behaviors he wants a particular child to model, he still has the problem of communicating this to the child, and being sure that the child knows what he is to model. In other words it is important to highlight the desired behavior, so that the youngster does not imitate the wrong behavior. For example, when learning to figure skate, a student may imitate his instructor's loops and turns; on the other hand he may inadvertently imitate the instructor's style of lighting a cigarette, the way he wears his hat, or the phrases he uses, instead. If he imitates all of these and does not learn to figure skate, he is wasting his time as well as the instructor's.

There are several ways of making clear just what it is that the child is to imitate. This can be discussed with him, so that mutually acceptable agreement is reached about the behaviors to be learned (Frey \& Meyer, 1965; Croxton, n.d.). One can actually demonstrate the desired behavior, by literally saying "watch me" (in real life); or the worker could engage in a role-playing situation in which he 
simulates the situation in which the child is to learn how to behave in a particular way, and then acts the child's part in that situation, modeling the correct behavior. If he does this, he must then give the child a chance to practice the behavior in a role play, so that the worker can let the child know how well he is doing.

It is also important that the worker specify what it is about a situation that leads him to select the particular behaviors he wants the child to model, and why he uses them at a particular point in time. For example, if he wants a child to learn tact by imitating his tactfulness, the child needs to know what cues the worker is responding to in a specific situation and why the worker selects particular tactful behaviors to be used at a particular moment. It is necessary, therefore, to tell the child which cues the worker is responding to in a situation if he wants the child both to imitate his behavior and to behave in that way at the appropriate time (Thyne, 1963, pp. 62-87).

\section{Rewards}

Research suggests that an observer is more likely to imitate a model when the observer sees the model rewarded for the behavior the model wants the observer to copy, providing the observer also wants those rewards (Bandura \& Walters, 1963). Rewards can take many forms: praise, money, status, having another person do something wanted that is pleasing, and so forth. The housemother who expresses affection through a hug may get a hug and a smile (both are rewards) in return. The child care worker who responds to one child's blow-up with a calm voice, carefully finding out how it all got started and trying to teach the child a more constructive approach for future occasions, demonstrates to all of the other children who are watching a way of getting a calm and friendly response (a reward) from a child who usually responds to people explosively. Accordingly, once a worker has decided on the behaviors he wants his children to model from him, he needs to plan ways of making them aware of the rewards he receives for the behavior that he wants them to imitate-rewards that are (a) specific, (b) clearly related to the behavior he wants modeled, and (c) attractive to the children.

Unfortunately this is easier said than done. Child care workers are usually not flooded with rewards-quite the contrary. If they do something well and receive praise from their supervisor, this is often 
communicated out of sight of the children. Their pay check, a significant reward, is usually handled privately, and it is a reward for the performance of a total job rather than any specific act. Such a reward is associated with status, and can make a model more attractive in general; but a reward for a specific behavior, given to the model in the presence of the observer, increases the likelihood that that behavior will be imitated. Child care staff members in small institutions are not usually in situations in which they can receive promotions (a significant reward); in a large institution, a promotion may mean that the individual changes his locale, is no longer a part of that cottage or ward, and is therefore no longer available as a model.

For this reason, ingenuity must be used to make children aware of the rewards that a child care worker receives, and the rewards selected for highlighting must be those rewards the child wants for himself. One such reward is decision-making power-that is, the ability to make (or have a major part to play in making) decisions that affect his cottage or ward as, for example, when youngsters are to be discharged or admitted, what is to be done about particular equipment needs, or when a child should make a home visit. These decisions are often made by administrative or social work staff, with little if any attention to the child care worker's opinions; when this happens, the children correctly read the implied message, which is that their child care staff member is seen as being incapable of participating in such decision making and is, in fact, relatively powerless. If and when this happens, a child correctly perceives that the organization views the child care worker as incapable of making an effective contribution to decision making, and has therefore withheld the right to exercise "power" which rewards effective performance by the child care worker.

Another reward that might be meaningful to a child is respect: the esteem one receives for a job well done. Administrators, psychiatrists, social workers, and other significant members of the institution's staff might be encouraged to offer praise to a child care worker in the presence of the children when something is well done. There could be many opportunities for such an exchange: for example, on visiting the cottage or ward and finding it clean or redecorated (under the direction of the child care staff); or a visit following an upsetting incident that was managed well by the child care worker. In this latter example a social worker could say something like, "I'm certainly glad that you were here to work this out, Mrs. Smith. Everyone seems to be pleased with the results, thanks to you." And so forth. 
On the other hand child care staff often have rewards to dispense, running all the way from praise to a special "treat" such as a surprise picnic. (Note that the very fact that one has been given the right to dispense rewards can be seen by children as reward given to the child care worker for good job performance.) In recent years an entire treatment approach has developed around the use of rewards to modify behavior, based on learning theory (Liberman, 1972; Whaley \& Malott, 1971). There is considerable research and a growing body of experience to indicate that presenting an individual with something he finds rewarding immediately after he has performed a particular behavior increases the probability that he will perform that behavior again. It could therefore be possible to indicate to an individual that if he models a worker's behavior, he would be rewarded. Using our original example of Freddy and his temper, a child care worker might, after determining that Freddy likes having someone read him a story, make a pact with Freddy that every time he controls his temper in the ways that the worker models, a story will be read to him.

Making major behavioral changes does not happen overnight; in work with a boy like Freddy it would probably be wise to develop a series of subgoals, each one of which would bring him closer to the desired goal of total self-control. Accordingly a reward could be given if he begins to cut down on the frequency or intensity of his blow-ups; thereafter he could be guided, step by step-that is, from subgoal to subgoal-toward better and better self-control. Throughout this process, the child care worker would have to control his own anger in a consistently calm fashion. Obviously there will be occasions when the worker might become justifiably angry, but even so, he can model appropriate "angry" behaviors. If, for example, a child care worker is angry at a child for failing to do his homework, he might express his concern to the boy in private (rather than embarrassing him in front of the group); he might even feel moved to raise his voice and speak with considerable heat. Hopefully he would not slam doors, strike the child, or set some overly severe punishment that had little relevance to the incomplete work, for such behavior would obviously serve as negative modeling. Repetition has been found to be an important part of modeling. Seeing a model handle his own anger appropriately on one occasion is not likely to produce much behavioral change (Thyne, 1963, pp. 62-87). (My work with difficult children in institutions suggests that child care workers have more than enough opportunities to show repeatedly how well they can "keep their cool.") 
Experience has shown that, in time, Freddy would find self-control to be rewarding in itself, so that he would no longer need the tangible reward of the story. If the child care worker can continually demonstrate calm ways of responding to frustrating situations, Freddy will have a positive model showing him how to obtain the desired reward.

Incidentally, people who question this approach as "bribery" should ask if the reward is given in order to insure the child care worker that he can control Freddy and thereby "run a tight ship" (insuring peace and quiet for himself), or if the reward is given as a way of encouraging Freddy to try a new way of behaving that will eventually result in a real payoff for Freddy? If one answers in the latter terms, then the term "bribery" is inappropriate, because a bribe is always given in the interest of the person offering the bribe not the recipient.

Another approach to the whole question of rewards is to determine what the children in a worker's care find rewarding. In the short run, picnics, extra desserts, a story at bedtime, and so forth can all be rewards that children generally want. But in the long run, children in institutions want more basic things: they want protection and security while they are in the institution; they want to be discharged; and they want to go to some kind of stable situation in the community. Research suggests that if child care staff are in the position to have control of any of these three factors (rewards)security, discharge, and a good home-they are most likely to be used as models by their children (Bertcher, 1966).

Unfortunately child care staff members are not always in a position to provide the protection and security their children want and deserve. Studies have shown that children in institutions are often victimized by the other children who have lived there for a longer period of time (Polsky, 1962, pp. 89-109). Polsky's study showed that child care staff had turned over a major portion of the control of a cottage to its oldest residents. For example, when a new youngster misbehaved, the housefather asked the older boys to "straighten the new boy out." This "correction" often took place behind the cottage, and involved physical mistreatment of the new boy, which the housefather chose to overlook. In his view, he had done two good things: First, he had ended a discipline problem, and, second, he had given the older boys a taste of responsibility, which was "obviously" a constructive step.

In reality, of course, this housefather had surrendered his control of cottage life and neglected to protect a new boy against 
being victimized by the old timers. In similar situations child care staff often find that, over time, their ability to handle cottage living problems without the "help" of the older children is continually diminished. This means that the child care worker has less and less protection to give as a reward and is therefore likely to be viewed as a poor model. Polsky's study supports this observation, for, in time, new boys came to model themselves after the vicious behavior of the older boys in the cottage (not the housefather) and the cycle of victimization was perpetuated.

The importance of involving child care staff in making decisions about discharge was discussed above, but the third area (providing a good home after discharge) obviously presents a dilemma; first, because it is very difficult to control what happens after discharge and, second, whatever happens, child care staff are usually not involved directly in the process. However, following the logic of the research on role modeling, this may be an area that institutions should explore, again with the eye toward increasing the attractiveness and effectiveness of child care staff members as role models.

For example, child care staff members typically have little contact with parents of children in the institution (at least within my experience) because they often attempt to prove that they are better "parents" than the child's natural parents. Natural parents sense and resent this, especially when it is true. Therefore, direct interaction between child care staff and natural parents may be more trouble than it is worth. On the other hand child care staff members amass an enormous amount of information about their children; if this information could be given to parents, either in the form of written reports or through the social worker, it might prove helpful in improving the child's homecoming. When a child is going to a new foster home, direct contact between child care staff and the potential foster parents should not be so emotionally tinged, and could therefore prove useful. If a child knew that his child care staff worker would be involved in some constructive way in his postdischarge situation, he might view this involvement as potentially rewarding, and be more likely, as already discussed, to model his behavior after that of the child care worker.

\section{Similarity}

Another way to increase the likelihood that particular behavior will be modeled is to make the child more aware of the similarity 
between himself and the model (Latane, 1966). It is this notion that has led the poverty program to employ large numbers of poor, black, young adults from the neighborhood to work with black teenagers in an attempt to help the teenagers become more employable, less delinquent, and so forth. The idea has been that these young adults would perform their tasks in such a way they would serve as models of good employee behavior; that they would avoid criminal acts and thus demonstrate that the "straight life" is the more desirable path to follow. (Obviously, there are other reasons for employing such persons, but the potential modeling impact is viewed as a basic reason for employing neighborhood residents.) To the degree that ideas about similarity are true, a worker has to ask himself how his age, sex, race, work history, and so forth, affects the likelihood that he can serve as the best role model for his children.

Although similarity may make it easier for a child to identify initially with someone, the work of some authors suggests that differences between the observer and the model are less important if the observer is aware of the fact that the model is expert in something he would like to become skilled in doing himself (Hovland \& Weiss, 1951). I recall a 12-year old black boy who identified strongly with a white 28-year old recreation worker because of the latter's considerable talent as a painter and potter. The boy had a natural artistic bent, and became very attached to the staff member because of their common interest in art. In part this occurred when the boy saw the staff member praised (rewarded) at different times for some of his art work. Subsequently the boy was more open to attempts by the recreation worker to influence him and, for example, began patterning himself after the staff person's friendly manner toward other children by decreasing his bad habit of teasing younger children viciously.

On the other hand the worker may not have particular talents that a child could model; or the child might see himself as being very dissimilar from the worker. Such a youngster might think, "Sure, he can do that, but I never could." This may be a point at which it would be a good time to introduce someone else as a model. Some programs might, for example, make use of college students as "big brothers" and "big sisters." For example, one institution for young adolescent girls used college girls as "big sisters." In this instance it was hoped that the older girls would provide a model of appropriate study habits for girls who had notoriously bad school records.

Some programs recruit big brothers and sisters from within their own population; this is fine, providing that the older child is, in fact, 
a good model of the kinds of behavior that are desired, and will not use his position of power to take advantage of the "little brother" or "sister." This means that the adoption of such a plan requires someone to supervise it and train the older children to be good models. On the other hand there is evidence to show that older children who are in trouble in public schools can serve as effective tutors for younger children who are also having school problems (Lippitt \& Lohman, 1965). Not only have they provided good models for the younger children, the tutors often find themselves changing their own attitude toward the school, because they are seen as staff members, to a degree. This idea might be worth exploring in residential institutions for children.

One of the most potent models for a child is another child who is his own age. Pete's hobby is nature-lore, and he is very kind to animals; Billy is cruel to animals and could profit from modeling Pete's kindly behaviors to little creatures. Larry blows up when anyone deprives him of something he wants, but Jim shrugs this off complacently, mumbles a few unpleasant words to the offender, and then ambles off to greener pastures. If Billy could model some of Pete's compassion, Larry some of Jim's calm, they would both benefit greatly. But Pete also can be very cruel to smaller children, and Jim's complacency is part of a general tendency to stay uninvolved with other people, for he is the isolate who would rather be by himself and destroy people (in his mind) than grapple with them in real life. In short, if these boys are to learn from each other, someone (the child care worker, for example) needs to be highlighting those behaviors that should be modeled.

One way of doing that is for the worker to be the provider-for example, of rewards of praise to Pete (if he wants Billy to model Pete's behavior) but at the same time making clear that the worker's praise is related to Pete's "compassionate" rather than his "bullying" behavior. Another way to do this is to engage the group in role-playing sessions in which effective ways of dealing with problem situations are demonstrated for a cottage member by one of the other youngsters in the group. Still a third approach might be to engage big brothers and big sisters in a special training program designed to teach them how to perform their role effectively. These youngsters could then be encouraged to imitate correct behaviors from the worker, and in turn present a model of good behavior to their younger "brothers" and "sisters."

It is essential, however, to avoid the trap mentioned earlier in reference to the study by Polsky - that is, the mistake of selecting children who are negative role models. Consequently, a basic 
condition for using some children as role models is that the child care worker be able to exercise considerable authority in cottage life. At the same time the worker must not perform in a domineering, punitive way, or he himself will become a negative role model.

There is a way in which child care staff can make their similarity to their children more visible and that is to share some of their own childhood experiences with their children. I recall a housemother who was worshiped by her girls, in part because, as they told me, "She used to ditch school, too, and she really knows what it's all about." The girls who told me that also made it clear that while this houseparent understood why they had trouble attending school, she insisted on their going. This exemplifies another important point about modeling, namely, that an observer is more likely to emulate someone who, though like him in ways that are significant to him (the observer) is also somewhat better than he; someone he wants to be like, but who is enough like him for him to think he can reasonably aspire to emulate, given time and effort.

\section{Further Discussion}

For role modeling of complex behavior to occur, a considerable amount of contact between model and observer is needed. For this reason child care staff members are likely to be among the best potential models a residential setting has to offer, providing the above conditions (clarity of behavior to be modeled, ability to receive and dispense rewards openly, and visible similarity between model and observer) are met. Child care staff are involved in all of the major and minor happenings that make up the every-day life of a child; they interact with him around the essentials of eating, sleeping, toileting, socializing, and so forth, and are therefore far more visible models for children than some specialists on the staff whose contacts with children may be limited to a weekly 1-hour therapy session. One of the major contributions child care staff have to make in the total treatment of the child is to serve as good role models. This suggests that it is imperative that child care institutions study the whole area of role modeling and consider ways of increasing the likelihood that child care staff will, in fact, be modeled. This paper has suggested several approaches to enhancing the effectiveness of child care staff as models; these suggestions obviously have implications for the design of institutions for children.

However, they also have implications for the child care worker himself. For example, let us look at power. I can recall that the 
institution I worked in used the professional staff to make all final decisions about discharge and intake of new children. Child care staff were not seen as having sufficient knowledge to make these decisions. They resented this exclusion. Several years after I left that agency, I paid it a visit. Many of the houseparents that I had known were still there, but there was a new administration. The houseparents had all benefited by being sent to a local university, where they took a course designed specifically for child care workers. They thought that it had been an excellent course and were now able to use correctly some of the technical "jargon" that had previously been in the private domain of the professional staff. The new director also had made it his business to include them in staff meetings, where decisions about admission and discharge were made, through group discussion.

But a funny thing had happened. Previously, houseparents had resented the fact that decisions were made by others. Now that they were able to join in making these decisions, they tended to abdicate their power, and ask the professional staff to make decisions for them. In terms of role modeling, they were failing to capitalize on newly acquired power, which could have helped them to be seen as more effective models.

The moral (such as it is) might therefore be that if organizations move toward creating the conditions whereby the child care staff can use role modeling more effectively, the worker's job will develop new challenges and he will need to be prepared to grapple with them. He will need to know himself better and be more willing to examine those things that he is doing that make him (at times) a negative model. He will need to know which of his own behaviors he wants his children to model, and develop ways of increasing the likelihood that they will, in fact, model those behaviors. He will need to consider carefully which aspects of his own life he is willing to share with them as a way of making himself appear more similar and therefore a more feasible model. At times he may need to step aside and work hard to make others the models for particular children. Hopefully the challenge involved will, as it has in the past, continue to engage child care workers in doing those things that will have the greatest payoff for their children.

\section{References}

Bandura, A., \& Walters, R. Social learning and personality development. New York: Holt, Rinehart and Winston, 1963. 
Bertcher, H. Factors that affect the attitudes of girls toward staff in a correctional institution. Unpublished Doctoral Dissertation, School of Social Work, University of Southern California, June 1966.

Bertcher, H., Gordon, J., Hayes, M., and Mial, H. Role modeling, role playing: A manual for vocational development and employment agencies. Ann Arbor, Michigan: Manpower Science Services, 1969.

Croxton, T. The treatment contract. University of Michigan School of Social Work, n.d.

Flanders, J. P., A review of research on imitative behavior. Psychological Bulletin, 1968, 69, 316-337.

Frey, L., \& Meyer, M. Exploration and working agreement in two social work methods. In S. Bernstein (Ed.), Explorations in group work: Essays in theory and practice. Boston: Boston University School of Social Work, 1965.

Hovland, C., \& Weiss, W., The influence of source credibility on communication effectiveness. Public Opinion Quarterly, 1951, 15, 635-650.

Liberman, R. P. A guide to behavioral analysis and therapy. New York: Pergamon Press, 1972.

Lippitt, P., \& Lohman, J. E. Cross-age relationships-An educational resource, Children, 1965, 12, 133-117.

Polsky, H. Cottage six. New York: Russell Sage Foundation, 1962.

Thyne, J. M. The psychology of learning and techniques of teaching. London: University of London Press, 1963.

Whaley, D. L., \& Malott, R. W., Elementary principles of behavior. New York: Appleton-Century Crofts, 1971. 